\title{
Adolescents' Antisocial Behavior in Schools: Examining the Influence of Poverty on Adolescents from Low Socio- Economic Families and Schools
}

\author{
Article by Memoir Chimwamurombe \\ Ph.D Education, Texila American University, Zimbabwe \\ E-mail:mchimwa@gmail.com
}

\begin{abstract}
The phenomenon of adolescents' antisocial behavior in schools has become a globally discussed issue. Even though there are various factors leading to antisocial behavior in adolescents in schools, poverty has been identified as one of the contributing factors. Adolescents from low socioeconomic status families are confronted by environmental pressures that lead to aggressive behaviors. This does not only lead to high failure rate, but also hinders the country's progress in terms of nurturing future human resource pool and the nation's productivity. The aim of this study was to examine the influence of poverty on adolescent misbehavior in Windhoek High Schools. A quantitative methodological technique was used to conduct the study. The adolescents for this investigation were from the age of 13 to 17 years who were in public secondary (high) schools in Windhoek, Namibia. The sample consisted of 300 participants who were chosen using stratified sampling throughout Windhoek from under privileged settings. A questionnaire was used to collect data. Ethical considerations were cautiously adhered to before and during the research process. Consent forms were given to parents and the purpose of the study was clearly explained to both parents and participants during data collection. The instrument's reliability was tested by means of a pilot study. Statistical Package for Social Sciences (SPSS) was used to analyze the data. The results were in the context of the influence of poverty on adolescents' behavior. Lastly, suitable recommendations were highlighted to fit the observed trends.
\end{abstract}

Keywords: Antisocial behavior, economic status, environment, school, Poverty and teenagers.

\section{Hypotheses}

Hypothesis 1: Prevalence of adolescent misbehavior from low income families will be significantly be evident in schools.

Hypothesis 2: There will be a significantly positive relationship between adolescents' antisocial behavior and poverty.

\section{Introduction}

\section{An introduction/background of the study}

The negative behavior of most adolescents have become a cause of concern in many African countries (Mahati et al. 2006 \& Matshalaga 2004). Governments, ministries, churches and Non-Governmental Organizations are facing challenges in shaping the behaviors of these children (Chingono et al; 2006). A lot of teenagers have serious behavior problems in schools that sometimes becomes very disruptive and mostly likely lead them to dropout from school. Educators encounter difficulties in dealing with adolescents who exhibit antisocial behavior. One of the most contributing factors to antisocial behavior in adolescents is due to poverty which paves way to inadequate schooling, to poor school performances increase the number of school drop-outs due to lack of parental care. This loop hole leads to delinquent and criminal behavior since no adults will be much concerned on the whereabouts these teenagers, (Chingono et al.; 2006 \& Mahati et al.; 2006). Research has proved that poverty is the major contributor to vulnerability of teens more so, if they are OVCs. $80 \%$ households with OVCs aged between $6-14$ years were reported not have enough money to meet their basic needs. This highlights that guardians/parents of OVCs teenagers are confronted by food, financial and educational crisis. Hence, research is also offering an insight into the 
DOI: $10.21522 /$ TIJAR.2014.04.02.Art023

ISSN: $2520-3088$

conceptualization of the of influence poverty on teenage misbehavior in schools. (Owens, 2002: 462) defines some teenagers as those, who have inappropriate behavior as, "Children, who are very violent, troublemakers, very active, and talkative, with short attention span in the classroom, the least co-operative and do not intermingle well with peers, intimidate others, fight and overall, just parade incorrect behavior."

This does not leave the Namibian community as an exceptional (Shirina, 2012). A teenager is defined as any between the age of 13 and 18 (Roos, 2011). To worsen matters, some teenagers are left to head households, some take up responsibility of caring their ill parents and are vulnerable to a number of ill effects, since they will be lacking precautionary guidelines as they grow up.

According to research, natural disasters, unemployment, underqualified and general credit crunch and numerous diseases such as cancers, malaria, tuberculosis HIV and AID (Hadi, 2001) have instigated poverty. The worst hit commodities of being already with inadequate infrastructure and limited access to basic services in most African Countries has a hand too. A study that was done by Dynah (2002), found that teenage misbehavior hardly happen in separation, and that severe behavioral difficulties commonly have a collection of problems. This study examined how poverty negatively influence behavior of teenagers in Windhoek High Schools. Furthermore, the study compared the relationship between adolescent behavior and poverty.

\section{Method}

There were 18 secondary schools in Windhoek, Namibia. The time this study was done. Six public schools in disadvantaged suburbs were randomly selected from the Ministry of Education list. All sampled schools had children coming low income families. Therefore the total population of these schools was 3045 . Of which 2993 learners are aged between 13 to 19 years. These students account for $98 \%$ of the total population. This became the study population and sampling frame. The sampling frame of learners' names was used to randomly select 300 participants. 50 adolescent learners were selected from each of the randomly selected from these six schools. The population study consisted of both boys and girls despite their ethnic groups. This research study used a quantitative methodological design which investigated the influence of poverty on adolescents from low socio- economic families and schools adolescents' antisocial behavior in Windhoek's High Schools. The statistical analysis (SSPS) was engaged to confirm and disapprove the pre-defined hypotheses for ensuing relationships between variables of the study (Higson, Smith \& Kagee, 2006; Mouton, 1996). A correlation research design was a statistical test to determine the trend or pattern for two or more variables (Cresswell; 2008).

\section{Results}

\section{Presentation and analysis of respondents' bio-data}

This section of the research work present the results of the statistical enquiry that has been conducted for the study. The results are obtainable as the results are shown as (1) descriptive information about low socio -economic status of families and adolescent's antisocial behavior (2) the interactive characteristics between school environments and adolescents' misbehavior (3) analytical characteristics of adolescents antisocial behavior in different family environments. In this study, a diversity of statistical calculations were executed. Statistical Package for the Social Sciences 18 (SPSS) was used for all the statistical calculations.

The following table is a guide to abbreviations used in the analysis of the data:

Table 1. Abbreviations

\begin{tabular}{|l|l|}
\hline Abbreviation & Variable \\
\hline & \\
\hline IBCL & Individual Behavior Checklist \\
\hline AMB & Adolescent Misbehavior \\
\hline ASB & Antisocial Behavior \\
\hline
\end{tabular}




\section{An overview of the analyses}

The hypotheses below for this study were framed centering on the aims and objectives of the research topic and are as follows:

Hypothesis 1: Prevalence of adolescent misbehavior from low income families will be significantly be evident in schools. This hypothesis was tested by independent $t$ tests, Means $(M)$ and Standard Deviations $(S D)$.

Hypothesis 2: There will be a significantly positive relationship between adolescents' antisocial behavior and poverty. This hypothesis was tested by a dependent $t$-tests and Spearman Correlations.

\section{Internal consistencies of measures}

This research study concentrated on construct validity. This helped the researcher to explore the degree to which the constructs were effectively operationalized. This was depicted by the scales selected to measure the influence of poverty on antisocial behavior of adolescents from disadvantaged families or home and school environments which allowed inferences about the relationships between variables (internal validity). More so, the sample was a good representation of the population from which it was drawn (external validity). In addition, adolescent misbehavior properties reliability testing was used by applying a recognized measure, the Cronbach's alpha. This was a test reliability procedure that required merely a single test administration to give a distinct estimation of the reliability for the test given (Gliem et al. 2003).

The Exposure Peer Pressure Instrument (EPP) was used (Allen \& Yen, 2002) together with the Child Behavior Checklist (ICBCL) as questionnaires. The EPP was used to as a measure to control the peer pressure exposure of adolescents. The ICBCL was used to measure the individual adolescent's behavior. The Cronbach alpha was also was applied as the reliability technique since it needs a single test administration to give a distinctive estimate of the reliability for a given test (Gliem, et. al.2003). Table 2 shows the Cronbach alpha coefficients for antisocial behavior in adolescents in schools.

Table 2. Internal consistencies of child behavior checklist

\begin{tabular}{|l|}
\hline Instrument $\mathrm{n}$ (items) Alpha \\
\hline ICBCL 40.82 \\
\hline
\end{tabular}

The Cronbach Alpha coefficient for the ICBCL was .82. This Cronbach Alpha coefficient is within the standard limits according to Mckillup (2006) because they it is above .75 . Therefore the instrument was regarded dependable.

\section{A description of the adolescents' demographic set up}

\section{Living arrangements}

Demographics were measured by using a questionnaire demographic survey which requested participants to include age, gender, culture, type of families they were currently living in. The table below shows the population's households. The results show that $72 \%$ of the participants came from single headed (mother / father alone) or other people such as friends, pastors. This category also have children that came child-headed families. This information also shows that $39 \%$ of the participants lived with relatives. These relatives were indicated as aunties, brothers or any family member. This can be also an ingredient that leads in promoting adolescents misbehavior in schools because the nature of the home where the child is coming from has an impact in molding behavior. This also have a negative set up in providing for the individual adolescent adequately. Ethnicities represented comprised mostly of Vambos, Damara Namas, Hereros and Afrikaners. 
DOI: $10.21522 / \mathrm{TIJAR} .2014 .04 .02 . A r t 023$

ISSN: $2520-3088$

Table 3. A description of the adolescents' demographic set up

\begin{tabular}{|c|c|c|}
\hline Variable & Frequency $n=300$ & Percent \% \\
\hline $\begin{array}{l}\text { Who do you live with? } \\
\text { Both parents }\end{array}$ & 85 & 28 \\
\hline Single headed family & 90 & 30 \\
\hline family member & 69 & 23 \\
\hline Child-headed family & 26 & 09 \\
\hline other & 30 & 10. \\
\hline
\end{tabular}

\section{Number of members in household}

The number of family members living under one roof was an important finding. It indicated a living style and how food, attention and other necessary support system were being distributed in the house. Nowadays, people are living together as extended family due to deaths and other pressing needs such as illness that lead capable family members to take care of their relatives' children. This strain resources in the house and it triggers the survival of the fittest norm. This leaves the teenager in the house vulnerable. According to the findings, the data showed that the families consisted with members between three to seven (3-7) people. The biggest number was 28 . This participant lived in an Orphanage Home. $10 \%$ of these adolescents survived in a families with members ranging from 8-13.

\section{Accommodation of respondents}

The study shows that 79 percent respondents lived in shanty towns. There is high crime rate in this places such that teenagers who grow up there are already affected by life-style and are exposed to the society's misdeeds. This may lead children to become victims of manipulators who are older than them. They may end up being involved in different crimes such as alcohol and drug abuse, stealing, banking lessons fighting at school, robbery, just to mention but a few. These shanty town or informal settlement fails to provide conducive environments to adolescents since they are a lot of Shabeens or taverns (local bars) in their surroundings. As a result, one can claim that living in such environments has contributed an extra affliction to an adolescent who is already affected by poverty and lack of parental guidance.

\section{Parents' educational level and statuses}

It was discovered that 72 percent of the participants lived without both their parents. Most of these teenagers' parents were Grade 10 and 12 failures. Only 6\% of them had passed Grade 12 but could not afford to enroll in universities and colleges. The average salary of these parents was $\mathrm{N} \$ 1500$ per month. Most of them are street vendors and some rely on piece jobs. Others as cleaners and in shops. Middle aged men work as car washers. So it becomes extremely difficult for such parents to nurture their children properly and offer them with good guidance, education and health care. Some mothers had no schooling at all. Speaking English is a challenge, they only communicate in their mother tongue. So, the chances are so high that such parents will fail to raise their children well and afford them with health food, proper clothing and good education.

It was also found out that due the nature of their jobs, these parents live below the poverty line hence the fail to provide for their children's needs. Since these parents are always in search of part-time jobs and vending, there is no family time. So many things unnoticed in the house. As for adolescents, peers come to being and replaces their parents totally, hence they become vulnerable to abusive adults.

Antisocial Behavior: Table 4 below represents the mean and standard deviation for each of the 20 ICBCL-items for all the participants from poverty stricken homes and informal settlements in Windhoek. 
Table 4. Means and SD of items for child behavior checklist

\begin{tabular}{|l|l|l|}
\hline ICBCL(individual behavior checklist) & \multicolumn{2}{|l|}{$\mathbf{n = 3 0 0}$} \\
\hline Variable (Have you ever...............?) & Mean & SD \\
\hline Damaged school property(e.g. doors) & 1.30 & .50 \\
\hline Fought with another learner & 1.58 & .69 \\
\hline Smoked cigarettes & 1.23 & .42 \\
\hline Used drugs & 1.11 & .31 \\
\hline Drank alcohol & 1.42 & .49 \\
\hline Bullied another learner & 1.40 & .49 \\
\hline Stolen things from home/school./shops e.t.c & 1.65 & .70 \\
\hline Miss out lessons at school (s) & 1.34 & .48 \\
\hline Bribed other school learners/ prefects & 1.51 & .71 \\
\hline Disrespected teachers & 1.26 & .44 \\
\hline Written/drawn some things in school toilets & 1.16 & .37 \\
\hline $\begin{array}{l}\text { Written/drawn some naughty graffiti in(bad things) } \\
\text { school textbooks }\end{array}$ & 1.23 & .42 \\
\hline Lied to teachers/ other learners & $\mathbf{1 . 8 6}$ & $\mathbf{. 4 0}$ \\
\hline $\begin{array}{l}\text { Do chats using a cellphone when the teacher is } \\
\text { teaching }\end{array}$ & 1.41 & .29 \\
\hline Failed to do your school work/ home work & $\mathbf{1 . 8 5}$ & $\mathbf{. 3 5}$ \\
\hline Fought physically with a teacher(s) & $\mathbf{1 . 0 9}$ & $\mathbf{. 2 8}$ \\
\hline Argued with a teacher(s) & 1.23 & .42 \\
\hline Cheated in class & 1.48 & .50 \\
\hline Had a romantic/ a sexual relationship. & 1.75 & .38 \\
\hline Brought home clothes to school without permission & 1.37 & .48 \\
\hline
\end{tabular}

The highest mean scores are found for the item "Lied to teachers/ other learner $(s)(M=1.86, S D=.40)$. The second highest mean scores are found for the items "Failed to do your school work/ homework" $(\mathrm{M}=$ $1.85, \mathrm{SD}=.35)$ and "Had a romantic/ a sexual relationship" $(\mathrm{M}=1.75, \mathrm{SD}=.33)$. The lowest mean score is found for the item "had fought physically with a teacher(s)" ( $\mathrm{M}=1.09,=\mathrm{SD}=.20)$. These numbers are indicated in bold in the above table.

\section{Discussions}

\section{Introduction}

This section incorporates the results in Chapter 3 in order to discuss the drawn hypotheses of the study. The limitations of the study will then be presented. Limitations for the study will be presented. A conclusion will be clearly stated and recommendations for future research will be specified.

Two hypotheses were formulated to explore and investigate the specific objectives formulated. These hypotheses were:

Hypothesis 1: Prevalence of adolescent misbehavior from low income families will be significantly be evident in schools.

Hypothesis 2: There will be a significantly positive relationship between adolescents' antisocial behavior and poverty.

\section{Living arrangements and number of members in a household}

The living arrangement of any family matters much for every child, let alone an adolescent. Research has proven that parents with low income or low paying jobs have limited time spent with their children (Altschul, 2012; Duncan, 2010; HSRC, 2007; Chingono et. al., 2006, Hill \& Taylor, 2004). It has been established children from poor background are confronted with many barriers in life. For instances, lack of resources that are essential for use at home and school. These children are said that they end up being 
DOI: 10.21522/TIJAR.2014.04.02.Art023

ISSN: $2520-3088$

traumatized due their living arrangements and the big number of people living under one roof (Steadman, 2010 \& Ellis, 2008). This has a potency to negatively sway adolescent to antisocial behavior due to not having enough parental guidance. In addition, most single parents face financial challenges to provide for their teens, hence they are forced to indulge in mischievous activities in order to fill the gap being created by parents. The result showed that $39 \%$ of the adolescents were staying with relatives. These relatives were indicated as aunties, brothers or any family member.

\section{Accommodation of respondents}

As evident in the results section that 79 percent of the respondents lived in an informal settlements. The houses are made out of iron sheets, plastics or wood. There is no proper sanitation and the area is too crowded. There is high crime rate in this places such that teenagers who grow up there are already affected by life-style and are exposed to the society's misdeeds. With the same voice, (Rima 2008) pointed out that residential settings must have decent qualities, which are supportive and developmental not dangerous and destructive since this have a big influence on adolescents' lives (Gutek, 1984). This may lead children to become victims of manipulators who are older than them. As a result, one can claim that living in such environments has contributed an extra affliction to an adolescent who is already affected by poverty and lack of parental guidance.

\section{Parents' educational level and statuses}

The family background has an important role to play in adolescents. Research proves that the parents' educational level and income are major contributor towards adolescents' behavior and their academic at school (Altschul, 2012 \& Noble et. al. 2015). Most parents that are less educated have difficulties in spending time with their children. They find it worthy to spend most of their time searching for work, laboring for food and money (Smith 2016). Some men decide to become drunkards to hide their feelings and to console themselves (Green, 2010). This is so much true because these parents are even ashamed to air their views because they undermine themselves. In agreement, Pryor \& Rodgers (2001) highlighted that if adolescents senses that they are not given attention by their parents, they engage in stressful activities. This has a negative impact on the teen who ends up imitating their parents, and do away with mischiefs and end up dropping out from school. Then, they become parents who will raise their children the same way they were raised and it will then became a poverty trend for the family.

\section{Antisocial behavior}

It was discovered that almost every adolescent that took part in the survey had strayed in one way or another. A questionnaire that was given to them showed that these teens are already active in adultery, drugs and drinking. This is the reason for high failure rate in Windhoek. Teenagers are busy with such activities instead of studying. Misbehavior with high scores were associated with drinking, drugs, smoking, bunking lessons, absenteeism and not paying attention in the classroom. Among these, bullying others and being involved in fights were evident misbehavior traits in most learners. This tallies with Owens (2002)'s finding in which it was mentioned that nowadays adolescents are being tangled in different crimes such as alcohol and drug abuse, stealing, fights at school, robbery, just to mention but a few. These are results of what they see in the shanty towns or informal settlement they live.

\section{Conclusion}

Adolescence are children between the ages of 13 to 17 years. During this phase, these children are very vulnerable and issues like poverty of the family destroys their ego. This research has revealed that issues such as the family structure, its arrangement, the location they are being raised, their parents' educational level and status a has a big impact on their behavior. The environment factor should not be left out. Children learn through imitation. So by raising a child in an informal settlement such as shanty towns or squatter were crime rate is high and indecent behavior is being displayed, is only risking the life of the teenager. However, no one want such a life, it is due to low income that lead people to be left with no choice but to live in indecent areas. Most adolescents are who they are because life experiences have taught them that. 
Nevertheless, as disturbing and complex the situation may seem, the adolescent can be helped in order for them to secure better future lives. Some remedies for this situation are outlined below.

\section{Recommendations}

The emphasis of this developmental research has often focused on the influence of poverty on adolescents' antisocial behavior schools. Vital insights were provided in this study to widen our understanding the behavior of high school children in informal settlements. The following recommendations are based on the results of this study;

- The Government of Namibia should see to it that the Harambee Prosperity Plan is accomplished and that it should benefit the rightful people that is, those living in poverty

- Sport activities are not a priority to the countries. Free Leisure Facilities must be available to all in order to remove teens from the streets. Recreational activities will remedy the situation. Form compulsory social clubs e.g. sports clubs which will also accommodate the less privileged adolescents who cannot afford to affiliate to current expensive clubs that are in existence.

- Lastly, the food banks must managed by people with people at heart. Food rotes in Food banks while people are hungry out there. If these parents are guarantee of having food on the table they may refrain from crime and also be able to spend time with their children as expected of them.

\section{References}

[1]. Allen. J. \& Yen, W. M. (2002).Introduction to measurement theory. Long Grove: IL. Waveland Press.

[2]. Altschul, I. (2012). Linking Socio -economic Status to the Academic Achievement of Mexican American Youth through Parent Involvement in Education. Journal of the Society for Social Work and Research 3 no.1: pp13-30 DOI 10.5243/jsswr.2012.2. University of Denver.

[3]. Chingono, A., Rusakaniko, S., Mahati, S.T., Mupambireyi, P.F., Chandiwana, B. (2006). Psychosocial Conditions of Orphans and Vulnerable Children in two Zimbabwean Districts. (Ed.) Cape Town, South Africa.

[4]. Cresswell, J. W. (2008). Educational research: Planning conducting, and evaluating quantitative and qualitative research. ( ${ }^{\text {rd }}$ Ed.). New Jersey: Pearson Prentice Hall.

[5]. Duncan; P. (2010). Family, School and community as Partners. Van Vyk Publishers. Pretoria.

[6]. Ellis, J. (2009). Basic Income Grants Alleviate Poverty in Namibia. Windhoek. Ministry of Basic Education, Sport and Culture, Namibia.

[7]. Gliem, F. \& Glem, R. (2003). Calculating, Interpreting and Reporting Cronbach's Alpha Reliability Coefficient of Likert Type Scales. Conference in Adult, Continuing and Community Education.

[8]. Green, L. (2010). Parent and Teachers: Partners or Rivals. Borough: Novello and Co Ltd.

[9]. Gutek, G. L. (1984). A history of the western educational experience. Belmont: Wadsworth.

[10]. Hadi, A. (2000). Child abuse among working children in rural Bangladesh: prevalence and determinants. Public Health, 114 (5),

[11]. 380-384.

[12]. Higson-Smith, C. \& Kagee, A. (2006). The Fundamentals of social research methods: An African perspective, (4th Ed) CapeTown: Juta \& Co.

[13]. Hill, N. E. \& Taylor, L. (2004), "Parental School Involvement and Children's Academic Achievement: Pragmatics and Issues", Current Directions in Psychological Science. DOI: 10.1111/.0963-7214.2004.00298.x, Harvard University and North Carolina University. Research Gate.

[14]. HSRC Press (2007). A Qualitative Research Report on Orphans and Vulnerable Children in Palapye. Gaborone, Botswana

[15]. Mahati, S.T., Chandawana, B., Munyati, S., Chitiyo, G., Mushangwe, W. Chibatamoto, P. \& Mupambireyi, P.F. (2006): A Qualitative Assessment of Orphans and Vulnerable Children in two Zimbabwean Districts. (Ed.) Cape Town, South Africa.

[16]. Matshalanga, N. (2006). Grandmothers and orphans care in Zimbabwe Harare: Southern Africa HIV/AIDS Information Dissemination Service.

[17]. Mckillup, S. (2006). Statistics Explained: An Introductory Guide for Life Scientists. Cambridge: University Press. 
DOI: $10.21522 /$ TIJAR.2014.04.02.Art023

ISSN: $2520-3088$

[18]. Mouton, J. \& Marais, H. C. (1996). Basic concepts in the methodology of the social sciences. Pretoria: HSRS Publishers.

[19]. Muraranganda, E. (2015). The Namibian Sun Newspaper: Minister's Response on Education SMSes. Windhoek. [20]. Noble, K.G. Houston, S.N., Brito, N.H. (2015). Family Income, Parental Education, and Brain Development in Child and Adolescents. Nat. Science 2015; 18(5) 545-552

[21]. Owens, K. B. (2002). Child and adolescent development: An integrated approach. Belmont: Wadsworth.

[22]. Pryor, J., \& Rodgers, B. 2001. Children in changing families: Life after parental separation. Oxford, UK: Blackwell Publishers.

[23]. Rima, B. M. D. (2008). Causes of peer pressure. [Online]Available on ww.well.sphere.co/wellpage/causes of peer pressure.

[24]. Roos, G. (2011). How Individuals, Environments, and Health Behaviors Interact Social Cognitive Theory. In: Health Behavior and Health

[25]. Shirina A. (2012). Effects of Family Breakup on Children: A Study in Khulna City .Bangladesh e-Journal of Sociology. Volume 10 Number 1, January. 138

[26]. Smith, A.R. (2016). "Parenting Involvement in Twenty-First Century School and the Implications of the Changing Family Structure. Recommendations for Leaders". Electronic Theses \& Dissertations Collection for Atlanta University and Clark Atlanta University

[27]. Steadman, H. (2010). The environment and adolescent's well-being: A longitudinal analyses. Journal of adolescent's age, 63(3), 697-713 